\title{
New Regional Wall Motion Abnormality by Non-invasive Imaging Technique
}

National Cancer Institute

\section{Source}

National Cancer Institute. New Regional Wall Motion Abnormality by Non-invasive

Imaging Technique. NCI Thesaurus. Code C119214.

A finding of decreased regional heart wall motion contractility, which is new compared to prior non-invasive imaging techniques. 